\title{
Justiça reparativa e direito penal canônico: aspectos processuais ${ }^{1}$
}

\author{
Reparative justice and canonical penal law: \\ procedural aspects
}

Resumo: Ao apresentar os aspectos processuais que encerram a teoria da justiça reparativa e sua possível aplicação nos processos penais canônicos, se oferece em primeiro lugar uma breve reflexão sobre a técnica da mediação e sobre os valores que nela encerram. Advirta-se para possibilidade de tê-las em conta, não somente como alternativas à celebração de um processo, mas também quando se coloca em prática. A reflexão conclusiva indica três problemas mais graves que
Abstract: Presenting the procedural aspects that surround the theory of reparative justice and its possible application in canonical penal proceedings, a brief reflection is first offered on the technique of mediation and on the values contained therein. Take note of the possibility of taking them into account, not only as alternatives to the conclusion of a process, but also when it is put into practice. The conclusive reflection indicates three more serious problems that

1 Oitava conferência proferida no II ${ }^{\circ}$ Simpósio Canônico "Questões seletas de Direito Matrimonial e Penal Canônico", promovido pelo Instituto Superior de Direito Canônico Santa Catarina em 8-9 de maio de 2018.

2 Presidente, Professor e Doutor no Institutum Utriusque Iuris da Pontificia Universidade Lateranense de Roma. Recentes publicações do autor sobre o tema da conferência: Convincimento, certezza e motivazione: l'esperienza canonica, en Criminalia, 2013, pp. 163-180; Diritto processuale canonico ( $6^{\mathrm{a}}$ edición), Roma, 2012; Relación entre las pruebas y la comprobación de la verdad en el proceso canónico, en Anuario de derecho canónico 1, 2012, pp. 11-36; com C. IZZI, Pastorale giudiziaria e prassi processuale nelle cause di nullità del matrimonio dopo la riforma operata con il Motu proprio Mitis Iudex Dominus Iesus, Cinisello Balsamo 2017, 320 pp; com M. RIONDINO, Introduzione al diritto canonico, Milano 2016, 217 pp.; 2017 (2a ed.), 230 pp; Giusto processo e peculiarità culturali del processo canonico, Roma 2016, 200 pp; Libro VII: De los procesos. Comentario sub cc. 1400-1691; 1717-1752, in Comentario al código de derecho canónico, Edicep, Valencia 2016 (16a. ed.). 
comporta atual tendência a evitar a via judicial na aplicação das sanções.

Palavras-chave: Mediação. Técnicas alternativas de resolução das controvérsias. Participação das vítimas. Garantias processuais. Investigação prévia. Valorização das provas. Decreto penal extrajudicial. present a tendency to avoid the judicial process in the application of sanctions.

Keywords: Mediation. Alternative techniques for resolving disputes. Participation of victims. Procedural safeguards. Previous research. Valuation of proofs. Extrajudicial penal decree.

\section{Introdução}

Sobre a incidência que podem ter para o ordenamento canônico os aspectos processuais vinculados à teoria da justiça penal reparativa não resulta fácil fazer um discurso sistemático. A razão principal é que, nessa visão do direito penal, tanto na doutrina extra canônica ${ }^{3}$, como nas normas internacionais e nacionais que se tem eco na mes$\mathrm{ma}^{4}$, os elementos processuais, em sentido estrito, caso desapareçam, como se entenderia que, para alcançar objetivos substanciais da justiça reparativa, teria que renunciar a pretender pronunciamentos judiciais, promovendo em seu lugar acordos de tipo conciliativo, que não são fruto de procedimentos legais rigorosamente estabelecidos em seu início e desenvolvimento, mas técnicas de confrontação mais flexíveis. Tais técnicas, em seus aspectos comuns, podemos considerá-las bem refletidas na técnica de mediação ${ }^{5}$.

O estudo do prof. Riondino constitui uma exceção a esse emparelhamento tão estreito entre os elementos substanciais da justiça penal reparativa e a técnica extraprocessual da mediação ${ }^{6}$. Para ele, no

3 Entre os autores mais representativos dessa teoria cf. F. Stella, Giustizia e modernità. La protezione dell'innocente e la tutela delle vittime, Milano, 2003.

4 Sobre as diretrizes internacionais cf. C. Mazzucato, Mediazione e giustizia riparativa in ambito penale. Spunti di riflessione tratti dall'esperienza e dalle linee guida internazionali, en L. Picotti, G. Spangher, Verso una giustizia penale conciliativa, Milano, 2002, pp. 85-110.

5 Sobre a relação estreita entre ambos aspectos, cf. L. Eusebi, Dibattiti sulle teore della pena e mediazione, en Rivista italiana di diritto e procedura penale 3, 1997, pp. 811-837.

6 Cf. M. Riondino, Giustizia riparativa e mediazione nel diritto penale canonico, Roma, 2012 (2. Ed.). 
esforço por aplicar as chamadas orientações ao sistema penal da Igreja, sem desdenhar o proveito que pode ser colhido na esfera canônica de um recurso adequado à mediação, ao menos em respeito a certos delitos, o autor as separa das facetas, permitindo distinguir de forma convincente entre ideais e procedimentos, com os valores da mediação, em sua relação com a orientação reparativa da justiça penal, buscam compreender-se como referências cobradas de exigências irrenunciáveis, ainda quando a intervenção penal requeira a abertura de um processo em sentido estrito ${ }^{7}$.

Segundo as sugestões se colocam no citado estudo, e tendo em conta alguns desafios da atualidade canônica, irei dividir a reflexão em quatro pontos. Indicarei em primeiro lugar o que poderíamos chamar de as bases da mediação como técnica e que se ajusta à justiça reparativa na aplicação das sanções. Apontarei depois as possibilidades e limites que, sobre esse argumento, se apresenta a normativa canônica. Em seguida formularei o que poderia se propor como aperfeiçoamento de iure condendo. Terminarei indicando alguns riscos que implica a carência atual de processos penais judiciais.

\section{Bases da mediação como técnica}

Começamos, pois, com as bases da mediação como técnica na intervenção penal. Levaria-nos para fora do tema ao pararmos para assinalar as raízes canônicas, por assim dizer, de práxis de mediação; não me refiro às bases bíblicas e patrísticas daquilo que poderíamos chamar justiça informal, perseguida desde a correção fraterna ${ }^{8}$, mas a um instituto estritamente jurídico, a Episcopalis Audientia em que, justamente por ser uma jurisdição outorgada em razão dos elementos profundos de coesão (como o compartilhar a mesma fé), para muitos autores se encontram as bases históricas mais sólidas da mediação ou, ao menos, da orientação conciliadora na administração da justiça ${ }^{9}$. Pa-

\footnotetext{
7 Ib., pp. 178-184.

8 É comum referir-se aos textos de Mateus (18, 15-17) e (1 Cor 6, 1-8) para sublinhar o caráter conciliador ao qual se deve aspirar a solução das controvérsias internas na comunidade eclesial

9 Cf. M. L. Hadley, Th spiritual roots of restorative justice, New York, 2001.
} 
ra os objetivos que agora nos interessam pode ser suficiente aludir ao período mais importante que, desde a metade do século XIX sobre os países de Cultura anglo-saxônica, foi alcançando a mediação como método de resolução de controvérsias, alternativo à justiça formal e aplicável a todos os setores, de forma singular aos conflitos familiares e comerciais ${ }^{10}$.

No âmbito penal, a mediação tem sido objeto de atenção no que diz respeito a delinquência juvenil, encorajando desde os organismos internacionais ao recurso da mesma como paradigma da chamada $\mathrm{Al}$ ternative and Restorative justice, exigência considerada muito urgente na hora de afrontar uma criminalidade em que os autores dos delitos não tem alcançado a maioridade, cuja condição jurídica é pois aquela do menor de idade ${ }^{11}$. Essa condição de sujeitos ainda em formação, por razão de maior peso para evitar procedimentos baseados em comprovação de atos do passado desde a superioridade e a frieza da lei e do juiz, é para buscar em seu lugar estratégias mais dinâmicas cujo horizonte se estabelece como objetivo à conquista de um futuro de relações renovadas segundo a justiça, desenhando-a desde o encontro criativo entre autor do delito e vítima, numa perspectiva de reparação satisfatória ${ }^{12}$.

Nesse contexto internacional cabe citar as chamadas regras de Pequim de 1985, cujo objetivo são as normas básicas sobre administração da justiça para os menores, nas quais se formula o desejo de recorrer a estratégias extrajudiciais em qualquer fase de um processo, no qual o imputado seja menor de idade ${ }^{13}$. O acordo da ONU sobre os direitos da criança de 1989 alterou o desejo na reclamação expressa aos ordenamentos estatais para serem profundamente revisados seus mo-

10 Sobre a variedade de âmbitos de interesses jurídicos nos quais se pode aplicar a mediação, cf. F. Scaparro, Il coraggio di mediare. Contesti, teorie e pratiche di risoluzioni alternative delle controversie, Milano, 2001.

11 Cf. M. Riondino, Il minore di fronte alla giustizia, en Commentarium pro Religiosis 87, 2006, pp. 149-170; Id., Justicia restaurativa y mediación juvenil. La experiencia en Italia, en Ministero della Giustizia (ed.), Nuove esperienze di giustizia minorile, Roma, 2009, pp. 27-40.

12 Cf. G. Mannozzi, La giustizia senza spada, Milano, 2003, pp. 47-50.

$13 \mathrm{Cf}$. United Nations, Standard minimum rules for the administration of juvenile justice. Beijing Rules 29.11.1985. 
delos de sanções aos menores, buscando alternativas adequadas para as suas personalidades ${ }^{14}$. No âmbito europeu, o acordo de Estrasburgo de 1996, assinalou a mediação como método e afirmou sem reticências o objetivo de evitar desde o princípio processos penais judiciais para delitos cometidos por menores ${ }^{15}$. Indica-se a mediação por considerá-la uma estratégia mais idônea para vários objetivos: para comprovar a personalidade do menor e seu ambiente sócio familiar, para analisar sua conduta criminosa no passado, para planejar uma futura atividade reparativa e também para poder avaliar com mais elementos a possível irrelevância e o caráter ocasional do delito ${ }^{16}$.

Está claro que alguns valores do instituto da mediação, no âmbito penal, são úteis, independentemente da condição jurídica do autor do delito, pois vão mais além das vantagens que cabe vincular à condição deste como sujeito na formação e com maior capacidade de encarar um futuro novo a partir da legalidade. Consequentemente, a mediação implica a possibilidade de reelaborar a experiência do mal provocado ou sofrido, ajudando a resgatá-la dos limites paralisantes aos que podem conduzir a simples busca de atenuantes, no caso do réu, ou a reafirmação hostil da dor experimentada, no caso da vítima ${ }^{17}$. Nesse sentido, podem ser enumeradas como valores a ter mais em conta nos procedimentos a comunicação entre os principais protagonistas dos fatos, a capacidade de apurar a irrepetibilidade de cada caso a partir de uma ótica de relação real, a personalização da pena em um horizonte de reparação, de reinserção e de renovada responsabilização e a confirmação da capacidade da lei, em si mesma, de incentivar ao respeito dos valores, sem fazê-los derivar do temor de sofrer sanções de conteúdo privativo e caracterizados por uma dureza abstrata além das relações humanas implicadas ${ }^{18}$.

14 Cf. United Nations General Assembly, Convention on the right of the child, 29.11.1989.

15 Sobre a normativa internacional e europeia remeto ao artigo de C. Mazzucato (citado na nota 2).

16 Cf. D. Pulitanò, Qaule futuro per la giustizia minorile, en Minori-Giustizia 1-2-, 2002, pp. 81 ss.

17 Cf. L. Eusebi, Riparazione e riconciliazione nel diritto penale, en Archivio Giuridico 137, 2006, pp. 269-301.

18 Cf. M. Riondino, Giustizia riparativa..., pp. 123-128. 
Esse maior alcance da mediação, independentemente da idade do imputado e da gravidade do delito, subjacente em uma recomendação (a n. 19 de 1999) adotada pelo Conselho da Europa ${ }^{19}$ e no documento final do X Congresso Internacional da ONU, celebrado em Viena em 2000, de onde se formulam os princípios básicos da justiça reparativa $^{20}$. Sobre tal documento, do ponto de vista processual, o conteúdo de maior interesse é a insistência de que o recurso à mediação penal não pode existir em detrimento aos princípios de garantia processual. Desta imprescindível exigência, sem entrar nas descrições detalhadas, podemos afirmar que, como instrumento jurídico, na técnica de mediação se está consolidando alguns institutos imprescindíveis, ainda dentro da flexibilidade e variedade de estratégias possíveis.

Entre elas, e como reflexo de valores que, sucessivamente, podemos considerar de utilidade processual na esfera canônica, cabe destacar, em primeiro lugar, a liberdade do réu e da vítima de acesso à mediação; essa liberdade, embora encerre alguns riscos inevitáveis de corte utilitarista (para ambos, autor e vítima) ${ }^{21}$, é indispensável que, para recorrer à mediação, não signifique deixar de lado a verdade dos atos, mas manifestar a vontade de classificá-los a partir de uma relação que permita elaborar e afrontar essa verdade com critérios mais autênticos ${ }^{22}$. Um segundo valor, sem diminuição do rigor sobre a prova e os atos, é a definição rápida do conflito, formulando decisões reciprocamente satisfatórias de respostas ao delito caracterizadas por seu conteúdo positivo e vinculadas às exigências da vítima ${ }^{23}$. Essa recíproca implicação das partes na definição do conflito nos leva a apontar, como terceiro elemento do instituto da mediação, o papel que cor-

19 Cf. Council of Europe, Raccommendation R (1999) 19 concerning the declaration of Basic principles on the use of restorative justice and mediation.

20 Para um comentário da declaracão remeto al artigo de C. Mazzucato (citado na nota 2), p. 173.

21 Sobre esses perigos adverte G. Mannozi, La giustizia senza spada..., pp. 378 ss.

22 Sobre a impossibilidade de renunciar ao descobrimento da verdade em qualquer processo eclesial cf. M. J. Arroba Conde, Relación entre las pruebas y la comprobación de la verdad en el proceso canónico, en Anuario de derecho canónico 1, 2012, pp. 11-36.

23 Cf. L. Eusebi, Profili della finalità conciliativa nel diritto penale, en AA. VV., Studi in onore di G. Marinucci. Teoria della pena e teoria del reato, II, Milano 2006, pp. 1109-1127. 
responde ao mediador, cujas qualidades têm que referir a capacidade de utilizar critérios de equidade na condução do processo, sem que isso signifique comprometer o respeito da legalidade e de suas garantias, porém melhor enriquecê-las a partir da adaptação às circunstâncias e às pessoas em causa ${ }^{24}$.

Concluo essa enumeração de valores que a práxis tem amadurecido em relação ao instituto jurídico da mediação penal, aludindo às diversas consequências que cabe estabelecer à luz dos resultados, positivos ou negativos, desta estratégia extrajudicial. Há de se indicar diante de todas as vantagens das diversas tipologias de medidas com que normalmente se define os procedimentos de mediação, isto é, a "colocada em prova", os benefícios de tipo não econômico (distintas do ressarcimento civil), de utilidade social e de reparação às vítimas, expressivas dos valores violados com a prática do delito, a inserção em estruturas adequadas de acompanhamento personalizado, com uma progressiva diminuição das eventuais restrições estabelecidas para o réu no exercício de alguns direitos, etc. ${ }^{25} \mathrm{O}$ êxito positivo de tais medidas, cuja duração não pode permanecer indefinida, comporta a extinção do delito e do processo penal. O êxito negativo da mediação ou as medidas alternativas definidas através dela, obriga a celebrar o processo penal, sem que o juiz possa utilizar como prova contra o imputado nada do referido no curso da mediação. Na doutrina se sustenta que caberia, sem embargo, usá-la em seu favor, sugerindo que o juiz, ao estabelecer a sanção, possa ter em conta a disponibilidade que teria mostrado o réu para assumir uma atividade reparativa ${ }^{26}$.

\section{Limites e possibilidades da mediação penal na esfera canônica}

Como já foi visto, a técnica da mediação, como reflexo processual dos ideais da justiça reparativa, adquire um valor central na comunicação entre o réu e a vítima, instaurando uma relação que se con-

24 Sobre o papel primordial do mediador e suas qualidades, cf. M. Riondino, Giustizia riparativa..., pp. 140-143.

25 Ibidem, pp. 124-126.

26 Cf. L. Eusebi, Ripensare la modalità della risposta ai reati, en Cassazione Penale 49, 2009, 4938-4958. 
verte no eixo tanto do procedimento como de sua definição. Nesse sentido, pode resultar pretensão excessiva referir seus valores ao processo penal canônico, vista a configuração da maioria dos delitos desse ordenamento, nos quais nem sempre cabe encontrar uma pessoa física como vítima, e onde esse papel corresponde frequentemente à comunidade eclesial enquanto $\operatorname{tal}^{27}$.

Referente às outras importantes consequências positivas dessa estratégia, como a possibilidade de evitar ou suspender o processo penal legalmente estabelecido (com todo sofrimento implicado, abstrações e frustrações) e o estabelecimento de medidas penais distintas das tradicionais sanções de tipo privativo, pode-se pensar que o sistema canônico tem pouco que aprender da mediação e que resulte incluso mais evoluído no modo de reagir diante dos delitos e menos exposto aos riscos de instrumentalização que pode acarretar o recurso à mediação ${ }^{28}$.

De fato, pela finalidade salvífica intrínseca ao ordenamento canônico e, sobretudo, porque o direito penal é somente um entre os meios que possui o sistema jurídico da Igreja para tutelar sua identidade e alcançar o bem comum, não somente tem uma previsão reduzida de delitos, mas que existem institutos que permitem reagir diante das suposições contempladas na lei segundo a orientação em que se inspira a técnica da mediação, com seus correspondentes valores. Entre esses institutos podem se indicar o frequente recurso ao estabelecimento de penas não determinadas (consistindo uma melhor adaptação da sanção ao caso concreto); a possibilidade de substituir a pena com uma penitência (com conteúdos portanto operativos e positivos, e não somente privativos); a não obrigatoriedade da ação penal (cuja promoção está submetida a impossibilidade de obter por outras vias as três finalidades, conjuntamente consideradas, de toda sanção); a isso se adicionam as medidas benignas que operam no foro interno ${ }^{29}$.

27 Sobre os casos em que a comunidade resulta ser a única vítima del delito no ordenamiento canônico, cf. M. Riondino, Giustizia riparativa..., pp. 169-174.

28 Sobre os aspectos culturalmente mais ricos do direito penal canônico, cf. G. Di Mattia, Il diritto penale a misura d'uomo, en Apolinnaris 64, 1991, pp. 747-770.

29 Sobre esses e outros elementos caracterísitcos do sistema penal da Igreja remeto às normas de ambos códigos vigentes indicadas por M. Riondino, Giustizia riparativa..., pp. 32-40; 50-53; 57-59 e 146. 
Ainda assim, têm aspectos nos quais o sistema canônico resulta processualmente menos adequado aos valores de justiça reparativa vinculados à mediação. Vou referir-me a três deles, indicando os limites que em cada um pode se dar sobre as garantias de participação de todos os indicados e sobre outros elementos de necessária consideração.

\subsection{Referência aos objetivos da investigação prévia}

Os primeiros limites dignos de menção se relacionam com a investigação prévia para a decisão de abrir o procedimento penal. Tal investigação, enquanto atividade de tipo preliminar, não tem regulação legal formal, por ter um único objetivo de coletar dados para sucessivas determinações. Daí que as normas se ocupem somente de delimitar o denotado objetivo, a saber, que uma vez recebida a notícia do delito, se adquire mais dados sobre sua existência real e sobre a imputabilidade, estabelecendo como única cautela no desenvolver da investigação não se coloca em perigo a boa fama de ninguém ${ }^{30}$.

Ao Ordinário, a quem corresponde decidir se terá curso ou não a investigação prévia (conjugando o grau de veracidade da notícia do delito e a necessidade efetiva de adquirir mais informações), corresponderá igualmente receber os autos e avaliar como terá que prosseguir o assunto: se concluindo o caso; se adotando medidas alternativas às sanções; se abrindo um processo para impor ou declarar uma pena e, em tal caso, se deve seguir a via judicial ou extrajudicial. Para tais determinações a lei exorta que o Ordinário se sirva do conselho de dois juízes ou expertos. É apreciado a proibição de confiar ofício de juiz, em eventual ao juízo penal sucessivo à investigação prévia, ao mesmo investigador, contudo, não existe norma semelhante em caso de processo extrajudicial, cuja condição pode ser delegada pelo Ordinário a quem fez a investigação ${ }^{31}$.

Assim estabelece o c. 1717.

31 Sobre esta e outras possíveis dificuldades do proceso extrajudicial, cf. G. Puntillo, Decreto penale extragiudiziale canonico e diritto di difesa, Città del Vaticano, 2010. 
O principal limite desta complexa normativa é o silêncio sobre a compreensão, já nessa fase, da disponibilidade que pode manifestar o réu em direção às soluções que logrem evitar o processo, e que permitam alcançar objetivos de revisão de sua conduta e de eventual reparação à vítima ou à comunidade ${ }^{32}$. Esta compreensão se transfere à fase processual; a única vantagem que ela pode ter reside em garantir melhor a liberdade de acesso a este tipo de solução, com menos riscos do que o réu preferir se render a elas, ainda que se considere inocente, ou em qualquer caso por motivos inaceitáveis ou carentes de autenticidade. Porém, se tem em conta que o sistema se orienta em direção à possibilidade de evitar tanto o processo como as penas, subtraindo a exigência de ponderar bem a necessidade de recorrer às sanções, não parece muito acertado prescindir deste aspecto na investigação prévia e transferi-lo somente para o juízo penal que, por outra parte deveria ser celebrado somente quando o Ordinário reconhece a inutilidade de outras alternativas, incluídas as correções ou admoestações formais. Essas, exceto na dimensão dos religiosos, não estão reguladas com suficiente precisão.

\subsection{Em relação à participação da vítima}

Um segundo limite importante tem por objetivo a participação da vítima enquanto as normas se refiram somente ao ressarcimento do dano, dispondo a possibilidade de persegui-lo tanto através de uma ação contenciosa que se adiciona ao processo penal, quanto manifestando a disponibilidade para uma solução extrajudicial com critérios de equidade, que corresponde ao bispo favorecer. Nesse sentido, posto que entre os requisitos que deve avaliar o bispo para decidir se abre ou não o processo penal, se encontra o de realização efetiva do restabelecimento da justiça (que inclui reparar o dano à vítima), não parece muito acertado que as normas sobre a investigação prévia não fazem referência a possíveis contatos entre o réu e a vítima, nem parece que

32 Considero muito corretas as observações e propostas que, a este respeito, apresenta o prof. M. Riondino, Giustizia riparativa..., pp. 166-169. 
tal silêncio possa explicar-se por temor ao colocar em perigo a fama de alguém ${ }^{33}$.

Por atribuir ao promotor de justiça ação penal se pode considerar satisfatória a participação da comunidade enquanto vítima final ou exclusiva do delito, enquanto que a intervenção de outras pessoas físicas como possíveis vítimas não está regulada de forma direta, nem no quê diz respeito à valorização do tipo de sanção mais adequada, nem em relação ao reconhecimento da efetiva correção do réu. Nesse sentido, ainda que as exigências das vítimas constituam hoje o ponto mais alto de preocupação na consciência moral da Igreja, tem que reconhecer que seu sistema processual manifesta este ponto como um calcanhar de Aquiles. No direito penal substantivo, se considera a pessoa física vítima do delito somente para prever a gravidade da pena, que se eleva segundo a posição eclesial da vítima ou, nos delitos de abusos sexuais, segundo a idade, provocando em tal caso uma reserva de competência absoluta ${ }^{34}$.

A falta de regulamentação sobre a participação das vítimas no processo não favorece um dos objetivos mais importantes da justiça reparativa, isto é, evitar que a imposição de sanções se percebam separadas em excesso os interesses comuns dos interesses das pessoas diretamente prejudicadas com o delito. Estabelecer modos adequados de participação das vítimas em processo penal ajudaria a evitar possíveis precipitações da autoridade em impor sanções, assim como instrumentalização ou denúncias carentes de verdadeiro fundamento. Nesse sentido, ainda que não se possa descartar que as vítimas sofreram com certos condicionamentos, sua participação no processo favoreceria os interesses de todos, incluindo o imputado que, na melhor doutrina, é considerado também vítima pelo fato de ter cometido o delito ${ }^{35}$.

33 Ibidem, pp. 169-174.

34 Sobre ambas questões dispõem os cc. 1362, 1370 y 1373.

35 Sobre a consideração do autor do delito como vítima do mesmo, o prof. Riondino (Giustizia riparativa..., p. 156) alude a alguns parágrafos da carta dirigida por Bento XVI aos fiéis da Irlanda (texto original em edição italiana do L'osservatore romano de 19.3.2010). 


\subsection{Sobre as condições para optar pela via extrajudicial}

Chegamos assim ao que creio que de maneira quase unânime se considera o limite principal das normas vigentes, isto é, as condições demasiadas genéricas que permitem hoje optar pela via extrajudicial, evitando as exigências rigorosas que implicaria a abertura de um juízo penal. Que as condições sejam genéricas resulta bastante claro se considera que a lei as reduz a existência de causas justas e se opunham a celebração do processo judicial. É verdade que, embora dessa forma tão débil, exigindo que tenha causas justas o ordenamento mostra uma preferência pelo processo judicial. Porém sobre o significado das causas justas (que em relação às graves e gravíssimas representam o grau inferior na hierarquia de motivos que estabelece o ordenamento canônico quando permite interrogar normas habituais) as interpretações são ambíguas e nem todas elas aceitáveis ${ }^{36}$.

A norma, desde seu significado literal, exige que as causas se refiram a atos que constituam um obstáculo direto para a celebração do juízo penal, pelo que não aparece aceitável converter tal causa e motivos que presumidamente aconselhe em seguir o procedimento penal extrajudicial, como pode ser a maior rapidez em declarar a resolução ou a urgência em impor a sanção ${ }^{37}$. Às vezes se induz como causar o possível escândalo que, na comunidade local, comportaria um processo judicial, dando por estabelecido que reconstitua menor escândalo para os fiéis impor penas sem juízos nem garantias ${ }^{38}$.

Menção à parte merece a falta de pessoal preparado, que constitui certamente um obstáculo sério para que se possam celebrar juízes penais; de tal circunstância não é sem embargo aceitar como motivo para evitá-los por sistema, seja porque nada tem a ver com as peculiaridades de cada caso, ao que necessariamente deveriam referir-se as causas justas, seja porque em certos casos deveria considerar-se melhor como situação injusta sofrida pela comunidade (e portanto não

\footnotetext{
36 Para uma crítica severa de algumas dessas interpretações, cf. G. Puntillo, Decreto..., pp. 62 ss.

37 Contra essa idea, cf. P. Ronzani, La pena ecclesiale, Padova, 2004, pp. 151-152.

38 Contra essa errônea interpretação, cf. Z. Grocholewski, Presentazione, en Z. Suchecki, Il processo penale canonico, Città del Vaticano, 2003, pp. 5-9.
} 
como motivo justo), seja enfim porque o ordenamento canônico, ao regular com flexibilidade a competência judicial, permite prover a carência de juízes sem permitir com isso deixar as garantias imprescindíveis que oferece a comprovação judicial de atos delicados ${ }^{39}$. É certo que a lei universal, ainda que tenha causa justas, não permite impor penas perpétuas por decreto extrajudicial, entre as que se inclui a demissão do estado clerical. Porém a proibição pode ser superada com a obtenção de faculdades especiais ${ }^{40}$.

Enquanto extrajudicial, a possibilidade de o Ordinário de proceder por decreto poderia ser considerada, ao menos na sua aparência, como opção mais facilmente harmonizável com os valores vinculados, na esfera penal, a procedimentos tais como a mediação. Porém deve recordar-se que o recurso a essas estratégias extrajudiciais está intimamente ligado à finalidade de evitar impor sanções privativas de direito, sem diminuir com isso a exigência de uma adequada comprovação dos atos e favorecer o contato entre o réu e a vítima. Essas três dimensões não tem lugar adequado no sistema canônico, de onde o recurso a via extrajudicial não tem limites em razão da natureza privativa das penas (mas somente de sua perpetuidade), de onde as normas que devem reger a necessária comprovação dos atos em tal procedimento se reduzem a demasiada genérica necessidade de recolher provas antes de emanar o decreto, quase nos mesmos termos estabelecidos no c. 50 para qualquer outro decreto administrativo, e de onde a participação da vítima não se encontra alguma menção explícita ${ }^{41}$.

Há de se esclarecer que, sem sair das margens de um procedimento muito sumário, no caso de decreto penal extrajudicial, a lei estabelece uma notável diferença entre o procedimento prévio e os de-

39 Sobre a necessária interpretação do instituto da competência judicial no processo canônico desde a tutela da comprovação da verdade e não desde valores comuns a outros ordenamentos (como o da distribuição territorial do poder), reenvio aos temas 9 e 10 do meu estudo sobre o processo, cf. M. J. Arroba Conde, Diritto processuale canonico, Roma, 2012 ( $6^{\mathrm{a}}$ edición), pp. 97-136.

São conhecidas as faculdades para tratar por via administrativa a questão da demissão do estado clerical que têm sido concedidas em tempos relativamente recentes à Congregação para Evangelização dos Povos e à Congregação do Clero.

41 Considero muito acertadas as observações que formula a respeito o Prof. M. Riondino, Giustizia riparativa..., pp. 178-184. 
mais decretos. Esses últimos se dispõe que se escute, porém somente na medida do possível, aquele que poderia se ver afetado em seus direitos pelo conteúdo do decreto mesmo. Se se trata do decreto penal a decisão deve estar precedida da comunicação ao réu das acusações e das provas, pelo que a obrigação de escutá-lo antes de determinar a resolução não deve se entender sujeita acepção alguma salvo, claramente, sua eventual ausência de procedimento.

\section{Três propostas de iure condendo}

Chegamos assim a formular sinteticamente algumas propostas de iure condendo, com a convicção de que tragam um aperfeiçoamento ao sistema vigente no horizonte de uma justiça penal reparativa, sem comportar ao mesmo tempo evoluções significativas na atual legislação processual. Apresento três possíveis propostas de aperfeiçoamento.

A primeira tem relação com as condições para optar pela via extrajudicial. A luz do quanto temos afirmado anteriormente, o recurso a essa via deveria limitar-se a dois tipos de situações. A primeira, tal como já permite a legislação vigente, aos casos em que as circunstâncias consintam prover com resoluções de natureza não privativa, como as penitências e outras obras alternativas de significado reparativo. É verdade que nem sempre se pode delimitar de antemão o suposto delito de que se trata em cada caso, pelo que pode parecer uma quimera pensar com a mesma antecipação em uma reação correspondente e adequada para adquirir o conjunto de finalidades vinculadas às sanções. Porém não deveria se esquecer que o reordenamento canônico não impede prover com medidas reparativas e alternativas, nem sequer quando estabelece uma pena obrigatória para determinados delitos ${ }^{42}$.

Um segundo tipo de situações em que o recurso à via extrajudicial resulta menos exposta aos convenientes que supõe este procedimento sumário são os casos nos quais existam provas irrefutáveis do

\footnotetext{
Assim o estabelece o c. 1344 em determinado suposto entre os que cabe mencionar a eventual sanção imposta no foro civil. Sobre isso, cf. M. Riondino, Connessione tra pena canonica e pena statuale, en AA. VV., Questioni attuali di diritto penale canonico, Città del Vaticano, 2012, pp. 199-225.
} 
delito como suficientes para garantir os direitos do réu, colocando-as em seu conhecimento, concedendo-lhe o tempo que se considera necessário para a sua defesa e sua possível refutação. É uma condição já existente no cânon paralelo do código oriental, que nesta matéria, resulta muito mais adequado que o código latino ${ }^{43}$.

A segunda proposta de aperfeiçoamento se refere a uma maior concretização dos critérios de valorização das provas segundo o c. 1572 , estabelecendo que os mesmos, de forma obrigatória, devem reger o discernimento do Ordinário antes de emanar o decreto penal extrajudicial e, dos quais, também obrigatoriamente, o mesmo Ordinário deve deixar registro específico e detalhado nas motivações de sua decisão ${ }^{44}$.

Essa referência concreta às provas e a seu sucessivo reflexo nas motivações do decreto permitiria ao menos, ainda que talvez tarde, que o réu possa recorrer com maior pertinência contra os atos ou contra as valorizações efetuadas pelo Ordinário, de modo que permanecessem resolvidas as eventuais lacunas do procedimento extrajudicial relativas às garantias do acusado. No primeiro projeto de reforma elaborado pelo Pontifício Conselho para os Textos Legislativos, anterior ao que tinha sido submetido à consulta, se incluía um cânon que desenvolvia muito bem, com disposições análogas aos do processo judicial, as exíguas disposições vigentes sobre o atual procedimento extrajudicial. Esse desenvolvimento tem-se reduzido sucessivamente, com o que os valores que poderia acabar a via extrajudicial, em relação à justiça reparativa e as técnicas de mediação, acabam-se perdendo em detrimento de outros também imprescindíveis nessas orientações.

A terceira proposta é de incluir expressamente a mediação, desenvolvendo para o âmbito penal o que já se permite no c. 1446, segundo as exigências que se têm amadurecidas nas normas extra canônicas. Isso requereria admitir que o imputado pode sempre propor uma

43 Pode facilmente apreciar-se a diferença entre o que establece o c. 1342 e o CCEO c. 1402.

44 Somente reforçando o vínculo entre a valorização da prova e a redação das motivações da decisão pode diminuir o risco de que o principio de livre valoraziçao desemboque em valoração arbitrária; sobre este ponto, cf. M. J. Arroba Conde, Convincimento, certezza e motivazione: l'esperienza canonica, en Criminalia, 2013, pp. 163-180. 
conduta reparativa antes que conclua o processo judicial ou administrativo. Se o juiz ou o Ordinário considerarem que a referida conduta é adequada para conseguir as finalidades das quais trata o c. 1311, poderiam declarar extinto o delido ou, ao menos, ter em consideração a referida disponibilidade no momento de determinar a sanção. Ao mesmo tempo, uma vez que tenha sido comprovada a culpabilidade do imputado, o superior ou juiz podem propor ao réu, à vítima ou a quem possa representar adequadamente o bem jurídico ofendido com o delito, o acesso a um procedimento de mediação penal conduzido por pessoas dignas, designadas pelo Ordinário. $\mathrm{O}$ que as partes declararem diante do mediador será submetido ao segredo e não pode ser utilizado no caso em que, sucessivamente, deva abrir-se um processo, ainda que o mediador deva informar o juiz ou a Ordinário do resultado da mediação e das condutas reparativas propostas ou já em andamento. Também nesse caso, se o juiz ou Ordinário considerarem positivo o resultado da mediação, relacionada às finalidades das quais trata o c. 1311, poderiam declarar extinto o delito ou, ao menos, tê-lo em consideração no momento de determinar sanção ${ }^{45}$.

\section{Riscos da atual tendência a evitar processos penais judiciais}

Embora o recurso a via extrajudicial possa se explicar em Igrejas de regime não comum, sua utilização comporta três problemas:

O primeiro é a falta de garantias que pode supor para o imputado um processo não judicial, embora é igualmente necessário evitar no juízo penal os excessos na interpretação de formalismo processual, cuja aplicação não pode resultar paralisante para a administração da justiça penal. Há casos que impressionam e são dolorosos em que se tem verificado essa direção excessivamente formalista, tanto em questão substancial como no processual. Penso no conhecido caso no qual o excesso de formalismo substancial recaía na fixação dos extremos de um delito de plágio, chegando a afirmar na sentença absolutória que tal delito não está contemplado no o ordenamento canônico e

45 Quando indicada nessa terceira proposta foi objeto de reflexão realizada pelo grupo de profesores do Institutum utriusque iuris em ocasião das contribuições à revisão do atual libro VI do CIC. 
que, devendo admitir sua existência de forma indireta, poderia afetar somente aos livros e não às anotações, com o qual se concluía afirmando que as anotações não são obrigatórias, já não são originais, mas queria-se citar a fonte utilizada. $\mathrm{O}$ excesso de formalismo processual consistiu em uma interpretação pouco equilibrada do direito de defesa, não porque o autor do plágio não tivesse sido citado ou ouvido, mas porque não o foi antes de proferir a primeira resolução de expulsá-lo da universidade, enquanto não chegou a apresentar-se na primeira convocação, dizendo depois que estava em viagem ${ }^{46}$.

Esta referência a um caso concreto tratado judicialmente somente na Assinatura, enquanto se havia começado a tratar o problema por via administrativa, creio que era útil para advertir o que normalmente considera-se um conjunto de complicações ou um excesso de formalismo no desenvolvimento do processo judicial penal, não me parecem circunstâncias cuja culpa esteja no sistema em si, mas a sua falta de aplicação é inadequada à compreensão no que se refere à rigorosa comprovação dos atos desde uma discussão sincera e transparente, sem que outros falsos temores possam justificar atuações carentes de qualidade e credibilidade jurídica. É certo que, entre os perigos de incorrer em atitudes passivas ou brandas, no exercício da potestade coercitiva, normalmente menciona-se, junto à complexidade dos objeti-

46 Se trata da única sentença escrita pelo então Cardeal Ratzinger em sua condição de juiz membro do Tribunal da Assinatura Apostólica (cf. Signatura Apostolica, coram Ratzinger, sentencia Romana, 27.10.1984, Dimissionis a munere docendi, en Il diritto eclesiástico 96, 1985, pp. 260-270); foi uma sentença dolorosa, na qual o Juiz Relator, que realizava pela primeira vez essa função, apresentou ao concluir sua demissão irrevogável, pois deve ter resultado muito difícil assumir em seu parecer semelhantes derivações formalistas, tendo passado a maior parte de sua vida, até então, em uma cátedra universitária de muito prestígio e exercitado como autor de escritos conhecidíssimos em sua originalidade. Aquela resolução foi, pois, considerada de modo unânime de pouca importância, porque apesar da absolvição, o réu não foi incorporado à sua cátedra Universitária, a qual se considerava que não poderia regressar, não tanto pelo plágio realmente cometido, mas assim se afirmou, por outros motivos de conduta pedagógica que talvez nunca teriam sido objeto de sincera comunicação entre ele e as autoridades da universidade, vítima de suas ações. O réu, aceitando sua exclusão da universidade obteve outras vantagens em sua posição eclesial, resultado que repugna o mais elementar sentido de justiça reparativa. 
vos que devem assegurar-se na imposição das sanções, a incerteza dos Ordinários sobre o procedimento que devem seguir-se para alcançálos. Por isso, a Santa Sé, no diretório sobre o ministério Pastoral dos bispos, exige com clareza a necessidade de superar essa passividade em situações que envolvem riscos de desorientação para a comunidade eclesial que tem em sua responsabilidade, solicitando-lhes agir com intervenções que conjuguem clareza e firmeza ${ }^{47}$. Tudo isso exige uma preparação suficiente aos bispos e uma preparação específica em direito penal aos clérigos e aos leigos, que possam colaborar com os bispos.

O segundo risco que provoca a falta de processos judiciais que caracteriza a atualidade eclesial em matéria penal é de incorrer inconscientemente na tentação de prover com resoluções com as quais se busca enviar mensagens exemplares em defesa dos interesses institucionais. Não é lícito concluir confundindo o obrigatório objetivo de restabelecer a justiça que identifica a Igreja, rompido com o delito, com a tutela à intransigência da tranquilidade institucional, querendo evitar através da imposição de sanções de forma precipitada, que a instituição possa ser acusada como corresponsável do delito. $\mathrm{O}$ Prof. Riondino adverte em seu estudo que a justiça a restabelecer com a sanção é a justiça salvífica que identifica a Igreja, da qual sempre pertence também o réu, ainda que se demonstre culpável $^{48}$; considerar inevitável a tutela do réu é ainda mais urgente em relação a comprovação real e sua culpabilidade, pelo que não cabe exercer sobre ele pressões encaminhadas para que aceite resoluções onerosas, dizendolhe que está em juízo um presumido bem da Igreja. Geralmente essas situações se verificam em relação a delitos que implicam também a jurisdição civil, sobretudo se esta já se tem pronunciado.

Nesse sentido, mesmo sem negar a necessária colaboração com outras jurisdições segundo as regras civis vigentes em cada lugar, me parece importante ter maior lucidez sobre os elementos de corresponsabilidade que poderia ter por meio de um delito, os que não pode ter jamais, não somente na esfera canônica, mas, nem se quisesse, na

47 Cf. a respeito n. 68 do diretório da Congregacão dos Bispos Apostolorum sucesores.

48 Cf. M. Riondino, Giustizia riparativa..., pp. 60-64. 
maior parte dos ordenamentos estatais, sem negar que alguns deles contenham aspectos muito expostas a provocar injustiça para a Igreja. A responsabilidade penal é sempre pessoal, mas a corresponsabilidade eclesial se enraíza na necessária vigilância e tutela antecipada, que nada tem a ver com a imposição precipitada de castigo ${ }^{49}$.

Ainda nesse mesmo contexto quero chamar atenção sobre os efeitos que às vezes comporta a celebração do processo penal na jurisdição estatal, uma circunstância que não deve interpretar-se como autorização para evitar abertura do processo canônico. A essa conclusão poderia se chegar, não somente por ceder inconscientemente à pressão que se poderia ter de fora da Igreja, mas talvez por confundir a norma que autoriza a não impor sanções canônicas se se considera suficiente o imposto pelo poder civil. Não se pode cair nesse erro, nem para aceitar resoluções de condenação nem de absolvição do réu. E eu acredito que, além das razões de direito substantivo, incidentes na orientação estritamente canônica das penas, há que se considerar as possíveis razões diretamente processuais, especialmente em tudo o que se refere à avaliação das provas e a aquisição da certeza moral. Acredito que seja imprescindível que Igreja conheça e se coloque com valentia a tomar distância expressamente das decisões da jurisdição estatal que tem fundamento em uma produção de provas ou em uma avaliação das mesmas que não seja congruente com as normas do processo canônico, de maneira especial com as disposições que protegem as garantias que correspondem ao réu no curso do processo judicial. Está claro que tampouco esse segundo tipo de risco se pode evitar se não tem maior capacitação para celebrar processos penais judiciais ${ }^{50}$.

Concluo assim indicando o terceiro risco que me parece implicar a carência de processos judiciais na esfera penal. Refiro-me justamente à pulverização indireta das garantias obtidas no novo Código e ao que creio se pode qualificar como orientação de renovação normativa desde a centralidade da pessoa na vida e missão da Igreja. Em âmbito

49 Cf. L. Eusebi, Responsabilità morale e giuridica del gobernó ecclesiale. Il ruolo dei vescovi in rapporto ai fatti illeciti dei chierici nel diritto canonico e nel diritto italiano, en P. Gherri (ed.), Responsabilità ecclesiale, corresponsabilità e rappresentanza, Città del Vaticano, 20010, pp. 83-104.

50 Em tal sentido se expressa também M. Riondino, Connessione..., 199-202. 
penal, o peso da orientação personalista se considera sobretudo no direito substantivo do livro VI, de onde a riqueza do patrimônio canônico mais genuíno se presta a conceber a sanção penal, tal como se assinala na moderna doutrina, não tanto e nem somente como privação de um bem, mas principalmente como projeto que responsabiliza em direção ao bem ${ }^{51}$. Porém creio que também no terreno processual, em concreto, nas disposições que regulam o processo penal judicial, é inegável o valor personalista que encerra algumas das novidades do Código vigente.

Entre essas novidades cabe destacar as que se relacionam com os direitos do acusado em todo o desenvolvimento do processo, e que não tem paralelo no Código anterior, como a que impõe pedir ao acusado que nomeie um advogado ou, em sua ausência, um lhe será designado (c. 1723); a que proíbe renunciar a instância penal sem consentimento do acusado (c.1724); a que atribui ao acusado ou ao seu advogado a última palavra no debate (c. 1725); a que obriga a pronunciar a sentença de absolvição, se consta que não houve crime, embora quando houvesse já prescrito ação penal (c. 1726); a que garanta o direito de apelação em ordem a demonstrar a inocência, embora quando se teria decidido prescindir da pena (c. 1727); a que proíbe pedir juramento ao acusado, declarando ao mesmo tempo que este não tem obrigação de confessar o delito (c. 1728) $)^{52}$.

Não quero deixar de referir ao processo penal pelos delicta graviora regulados no m. p. Sacramentorum sanctitatis tutela, no qual se estabelecem as competências da Congregação para a Doutrina da Fé como o Tribunal Supremo. No que se refere estritamente ao processo, nenhuma diminuição da tutela do acusado cabe temer. Poderia afirmar-se que essa diminuição se produz de forma indireta, ao se contemplar a possibilidade, para mim não aconselhável, de proceder por via extrajudicial, ainda que para impor a demissão do estado clerical. Considerando as condições estabelecidas para assim proceder, não se pode dizer que as normas do processo para tratar destes delitos reser-

Cf. M. Riondino, Giustizia riparativa..., pp. 54-57.

52 Para uma análise dessas novidades, cf. E. M. Egan, I processi speciali, en AA.VV., Il nuovo codice di diritto canonico. Novità, motivazione e significato, Roma, 1983, 499. 
vados foram baixadas, em relação ao presumido autor do delito, o nível de garantias que requer uma adequada orientação personalista. Ao mesmo tempo, são dignos de nota os avanços que essas normas contêm em relação a atenção que merece a vítima do delito, seja essa uma pessoa física, seja a comunidade eclesial em seu conjunto.

É desejável uma melhora no que diz respeito à comunicação, especialmente com a comunidade. E vale a pena avaliar se não seria melhor realizada com sujeitos distintos dos titulares na função de governo próprio ao que está imediatamente sujeito o presumido autor do delito. Trata-se de discernir em cada caso quem (por ser organismo colegial, ou tratar-se de uma pessoa ou de um ofício pessoal útil na causa concreta) pode ser representante significativo da comunidade, enquanto vítima do delito. Uma correta comunicação tanto ao réu como à comunidade, evitando comprometer sem necessidade a boa fama, porém também, sem desnecessário obscurantismo, é indispensável. Com isso diminuiriam os riscos de infringir as garantias processuais do réu e, ao mesmo tempo, se reduziria a possibilidade de que o necessário segredo se converta em uma arma para o réu, faltando à verdade, pode contestar presumidas as conclusões de seus direitos processuais ou, inclusive, o desconhecimento das imputações que a eles são feitas. Esta situação ocorre atualmente com demasiada frequência, criando ainda mais desconforto na comunidade e gerando divisões em seu meio.

\section{Bibliografia}

D. Pulitanò, Qaule futuro per la giustizia minorile, en MinoriGiustizia 1-2-, 2002, pp. 81 ss.

E. M. Egan, I processi speciali, en AA.VV., Il nuovo codice di diritto canonico. Novità, motivazione e significato, Roma, 1983, 499.

F. Scaparro, Il coraggio di mediare. Contesti, teorie e pratiche di risoluzioni alternative delle controversie, Milano, 2001.

G. Di Mattia, Il diritto penale a misura d'uomo, en Apolinnaris 64, 1991, pp. 747-770.

G. Mannozzi, La giustizia senza spada, Milano, 2003. 
G. Puntillo, Decreto penale extragiudiziale canonico e diritto di dife$s a$, Città del Vaticano, 2010.

L. Eusebi, Profili della finalità conciliativa nel diritto penale, en AA. VV., Studi in onore di G. Marinucci. Teoria della pena e teoria del reato, II, Milano 2006, pp. 1109-1127.

L. Eusebi, Responsabilità morale e giuridica del gobernó ecclesiale. Il ruolo dei vescovi in rapporto ai fatti illeciti dei chierici nel diritto canonico e nel diritto italiano, en P. Gherri (ed.), Responsabilità ecclesiale, corresponsabilità e rappresentanza, Città del Vaticano, 20010, pp. 83-104.

L. Eusebi, Riparazione e riconciliazione nel diritto penale, en Archivio Giuridico 137, 2006, pp. 269-301.

L. Eusebi, Ripensare la modalità della risposta ai reati, en Cassazione Penale 49, 2009, 4938-4958.

M. J. Arroba Conde, Convincimento, certezza e motivazione: l'esperienza canonica, en Criminalia, 2013, pp. 163-180.

M. J. Arroba Conde, Diritto processuale canonico ( 6 a edición), Roma, 2012.

M. J. Arroba Conde, Relación entre las pruebas y la comprobación de la verdad en el proceso canónico, en Anuario de derecho canónico 1, 2012, pp. 11-36.

M. L. Hadley, Th spiritual roots of restorative justice, New York, 2001.

M. Riondino, Connessione tra pena canonica e pena statuale, en AA. VV., Questioni attuali di diritto penale canonico, Città del Vaticano, 2012, pp. 199-225.

M. Riondino, Giustizia riparativa e mediazione nel diritto penale canonico $\left(2^{\circ}\right.$. Ed.).

Roma, 2012.

M. Riondino, Il minore di fronte alla giustizia, en Commentarium pro Religiosis 87, 2006, pp. 149-170; 
M. Riondino, Justicia restaurativa y mediación juvenil. La experiencia en Italia, en Ministero della Giustizia (ed.), Nuove esperienze di giustizia minorile, Roma, 2009, pp. 27-40.

P. Ronzani, La pena ecclesiale, Padova, 2004.

Signatura Apostolica, coram Ratzinger, sentencia Romana, 27.10.1984, Dimissionis a munere docendi, en Il diritto eclesiástico 96, 1985, pp. 260-270.

Z. Grocholewski, Presentazione, en Z. Suchecki, Il processo penale canonico, Città del Vaticano, 2003, pp. 5-9. 